\title{
Ready for the future?
}

\section{Pullman, Washington}

LAST week, 3,000 agricultural scientists around the world saw the future, and apart from a few technical glitches, dead spots and occasional lack of focus, it worked. An international symposium on plant biotechnology put on by Washington State University was the first interactive televised scientific conference to be broadcast worldwide, and although it was not without hitches it showed that that satellite networks are finally up to the task of video conferencing.

The symposium, a year in planning, illustrated strengths and weaknesses of teleconferencing technology. With an audience distributed at 70 viewing centres worldwide, it brought together plant biotechnology experts with scientists in developing countries who might not have been able to attend an international meeting. Conference officials estimate that at about half of the viewing centres, local organizers used the three-hour symposium as the nucleus of longer local meeting. Observers at all sites were able to fax written questions during the conference to Pullman; by mid-point, over a hundred questions had been received. Several dozen questions were answered on-air, and the others received written responses.

The conference featured two panels of plant biotechnologists, one group in Pullman, the other at the Max-Planck Institute for Genetics Research in Cologne, West Germany. Pullman's five-member panel was composed of scientists from the United States, Mexico and Australia, along with an American journalist - Jack Reynolds of the United States Information Agency - who served as moderator. In Cologne, Jozef St. Schell, director of the Max-Planck Institute, led a fourperson panel that included former International Rice Institute director $\mathrm{M}$. S. Swaminathan and Konstantin Skyrabin of Moscow State University.

Except for a brief loss of audio from Cologne and some minor production glitches, the conference was technically flawless.

Much of the success was due to redundancy in the form of duplicate equipment at every stage of link (which included seven satellites and an equal number of ground stations), and a large production crew of professionals and students from Washington State University's telecommunications programme.

But as technically impressive as the symposium undeniably was, it illustrated some of the traditional problems of international conferences, as well as some new ones. With an audience of biotechnology researchers, Third World agricultural scientists, students, and even Washington
State legislators, the conference oscillated wildly in tone, technical content, and direction.

A basic 15-minute taped primer on genetic engineering by Schell was immediately followed by a debate on the fine points of RFLP (no definition given) techniques by other panel members. Summaries given at the end of each onehour segment appeared to have been largely prepared beforehand, reflecting little of the unscripted debate. And a prepared presentation on the application of biotechnology to world food production by Robert Fraley of the Monsanto Corporation (one of the conference sponsors) came dangerously close to becoming a video advertisement for Monsanto products.

The basic problem, however, appeared to be that because little more than a 5metre satellite dish and a television set was needed to plug in to the conference, the audience became impossibly broad, ranging from leading researchers to interested but nonscientific members of the public. The organizers tried to include a little something for everyone, with the result that few participants seemed to find the conference very satisfying. An exit survey taken at the Pullman site showed that the symposium did a poor job of demonstrating research techniques, conveying useful scientific information or providing new research ideas.

On the other hand, most participants gave the conference high marks for providing access to scientists who would not otherwise have been available. And many said that the conference had been their first introduction to the concerns of the Third World - the issues of access to research, costs, and preservation of traditional farming techniques. In one exchange that clearly illustrated the debate within the developing world on the hazards of biotechnology, Luis HerreraEstrella of the Mexican Centre for Research and Advanced Studies (and a member of the Pullman panel) said that Mexico "is most interested in food production. The ecological impact [of biotechnology] is less important". But Indian scientist Swaminathan, speaking from Cologne, quickly jumped in to warn against the use of the Third World as a biotechnology laboratory. "I disagree that it does not matter as much in the developing world. Ecological groundrules must be the same wherever they are on the planet", he said.

Although the jury is still out on the scientific success of teleconferences, the symposium showed that electronic meetings can be substantially cheaper than their traditional equivalents. Total costs amounted to about $\$ 300,000$, the majority

\section{Trial approved for saliva test}

\section{San Francisco}

A NOVEL saliva-based test for HIV (human immunodeficiency virus) infection, which may ultimately lead to a 'do-it-yourself' AIDS test, has been approved by the US Food and Drug Administration (FDA) for human clinical trials. The technique, developed by Epitope Inc. of Beaverton, Oregon, may make AIDS testing simpler and more widely available because antibodies are collected from the mouth without the need to draw a blood sample.

In the test, a treated pad is placed between the gums and cheek for two minutes to collect antibodies to HIV, which are present in the saliva. The pad is then placed in a vial and mailed to a laboratory where it is submitted to the standard HIV test now used on blood samples. In preclinical trials on 600 patients, Epitope scientists report that the collection device has been perfectly reliable, leading them to believe the test will be "fully equivalent" to blood tests.

FDA approval will allow Epitope to carry out clinical trials for nine months at five sites nationwide, where matched samples of blood and saliva will be compared. If marketing approval is then granted, the company plans to make the device available worldwide. Potential users include police and emergency medical personnel who request frequent testing for HIV, and developing countries where blood testing may be impractical.

The company is now considering ways to address questions of counselling and anonymity that would arise with widespread use of the test. One option under consideration is that AIDS hotlines or counselling centres would be contracted to inform users of the results of their tests, and of what can be done following a positive result. Epitope hopes ultimately to produce an AIDS test, based on the saliva collection device, which could be conducted entirely at home.

Elizabeth Schaefer

of which was covered by in-kind donations from a half-dozen telecommunication companies. A traditional conference with the same attendance would typically cost the organizers about $\$ 1$ million and the participants another $\$ 3$ million for travel and lodging, according to Washington State University administrator Donald Hanna, who co-chaired the event.

But the larger lesson, he said, is that successful global teleconferences will have to cover fields that are changing too fast for the scientific journals to keep up with, stick to subjects like plant biotechnology and involve issues of worldwide importance, such as health, food, or population.

Christopher Anderson 